This is an Authors' Accepted Manuscript of an article published in SPORT IN SOCIETY, online first May 2016, copyright Taylor \& Francis, available online at:

http://www.tandfonline.com/doi/pdf/10.1080/17430437.2016.1179735

\title{
Understanding Sports Violence: Revisiting Foundational Explorations
}

Within this paper we discuss the importance of attending to definitions of 'violence'. Through a return to a selection of important foundational works, we attempt to unpack the fundamental meanings of violence in a general sense, and sport violence in particular. With a specific focus on the need for definitional clarity, and particular attention to the 'ritual' dimensions of sport violence, we argue that engaging with these concepts is essential when conducting research in 'violent' contexts. Based on a critical reading of a small selection of relatively recent scholarship in sports settings, we ultimately argue that without careful consideration of what can constitute 'violence', scholars risk misrepresenting the social worlds they investigate. In conclusion we call for researchers to enter into a dialogue with foundational explorations of violence and to pays far greater heed to the definitions favoured by practitioners who engage with apparent 'violence' on a regular basis.

Christopher R. Matthews

School of Sport and Service Management, University of Brighton, Eastbourne, UK Alex Channon

School of Sport and Service Management, University of Brighton, Eastbourne, UK

Corresponding Author:

Dr. Christopher R. Matthews, School of Sport and Service Management, University of Brighton, Eastbourne, UK

Tel: (+44)1273643746

Email: c.matthews2@brighton.ac.uk 


\title{
Understanding Sports Violence: Revisiting Foundational Explorations
}

\author{
Dr. Christopher R. Matthews (University of Brighton) \\ Dr. Alex Channon (University of Brighton)
}

In the academic study of sport, the term 'violence' is employed within various contexts to describe a multitude of actions, behaviours and phenomena. Despite being a morally charged term - and thus potentially politically active in its employment - it is a word commonly used in scholarly and popular discourse in an implicit and often assumed capacity. As such, Kimble et al $(2010,460)$, discussing sports violence, suggest, "this creates the unfortunate situation where an observed behaviour could be correctly viewed as either violent or non-violent". Here, the term's usefulness in an academic sense begins to falter. It is crucial to seek some level of affirmation over the meaning of terms that are regularly utilised within academic discourses. What is more, such a problem is particularly concerning here given the clear implications that the term 'violence' has for questions over the moral legitimacy of certain sporting practices.

With this in mind, several previous attempts have been made to refine, classify, delineate and confirm what is meant by violence in sport. The vital importance of such effort forms the conceptual basis of this paper, wherein it is hoped that revisiting a selection of some of these ideas might leave sport scholars better equipped to avoid the often implicit (and perhaps unintended) meanings that can become attached to the term 'violence' as a descriptor of sporting practices. In what follows, we explore some of the foundational and conceptual underpinnings of sociological definitions of violence in general, and sports violence in particular. At first glance this may seem to be an oddly retrospective step if the reader is familiar with the vast amount of published work within the area. However, as Kevin Young $(2012 ; 1)$ has recently argued:

Almost none of the colossal sociological/criminological literature [on violence] even mentions the types of violence that may be done in sport contexts, and it certainly does not take the next step to examine whether violence in different social institutions shares commonalities in cause, expression or outcome.

This is a field, then, that even with Young's (2012) recent and fairly comprehensive analysis still requires further sociological attention. Indeed, it is recent additions to the stock of knowledge concerning player violence in sport that are of particular interest here. Through an exploration of a particular selection of research from the previous decade, we attempt to outline the importance of engaging with foundational debates over the meaning of 'violence' within this scholarly work. We begin by briefly exploring the philosophical and conceptual grounds upon which these definitions are constructed.

\section{Defining 'Violence': Force and Violation}

What actions, phenomena and events can be subsumed within the term violence? Or perhaps more to the point, what is violence? Beneath this simple question lies a long history of implicit assumptions, anecdotal viewpoints and philosophical debate (see Sorel, 1961). As a point of departure, we begin unpacking the use of this term by exploring what appear to be two central themes. The goal is not to provide an exhaustive or mutually exclusive conception, but rather to signpost in broad terms the 
building blocks that together largely underpin contemporary understandings of violence. These initial observations provide the foundation for subsequent discussions and conclusions within this paper and may be of use more broadly for those wishing to gain conceptual purchase on the meanings of violence in general or sports violence in particular.

Within the extant literature, two salient and interconnected positions consistently resurface and provide the conceptual basis for sometimes opposing and sometimes complementary understandings and definitions of violence. These positions can be categorised as focusing on the perpetrator or the victim. When attention is upon the perpetrator of violence, the term highlights the intentional, destructive force that he or she projects towards someone or something (Audi, 1971; Litke, 1992). Henceforth referred to as 'violence-as-force' (Bufacchi, 2005), this is perhaps the most commonly employed and popular understanding of violence (Coady, 1986). Audi's (1971, 59) definition provides a useful starting point:

Violence is the physical attack upon, or the vigorous physical abuse of, or vigorous physical struggle against, a person or animal; or the highly vigorous psychological abuse of, or the sharp, caustic psychological attack upon, a person or animal; or the highly vigorous, or incendiary, or malicious and vigorous, destruction or damaging of property or potential property.

Such an understanding of violence can be deployed in a restricted (Coady, 1986) and descriptive (Platt, 1992) sense. In this way, specific actions and behaviours can be clearly marked out as constituting violence. Applying the term in this manner allows researchers to increase analytical clarity by focusing on the physical and psychological harm caused by an actor or actors.

A second definition of violence focuses on the victim, and the violation of that person. Referred to as 'violence-as-violation' (Bufacchi, 2005), this shift in focus enables a broader conception and utilisation of the term (Garver, 1977). Anything that transgresses what individuals consent to can now be considered violent; clearly, the verb 'to violate' can be interpreted in many, varied ways. As such, there are subtle and stark differences within applications of this definition. Salmi $(1993,17)$ offers an overarching position: "[violence is] any avoidable action that constitutes a violation of human rights, in its widest meaning, or which prevents the fulfilment of a basic human need". This wide (Coady, 1986) and expansive (Grundy \& Weinstein, 1974) conception of violence enables the (im)morality traditionally associated with the term to be employed polemically towards diverse phenomena (Platt, 1992). Subsuming the majority of physical and psychological violence, but not confined to such manifestly destructive acts, this definition "has effectively sensitised large numbers of persons to the morally dubious status of many social structures and practices" (Platt, 1992, 189). Thus, such a definition illuminates violence in both its obvious, tangible and direct forms - such as, for example, the physical violence of a gang-related murder - but also more subtle, systemic and insidious manifestations - such as the symbolic and structural violence of a society shaped by institutional racism, class-based poverty, and other contributing factors which may lead individuals to join criminal gangs in the first place.

Attempts have been made to contrast, delineate and prise apart these interwoven and overlapping understandings of violence. Keane $(1996,66)$ argues against the use of violence-as-violation when he notes that, "attempts (such as Johan Galtung's) to stretch [violence's] meaning to include 'anything avoidable that impedes human realization' effectively makes a nonsense of the concept." For Platt (1992), the moral significance of the term, which has resulted in its extended use to denote violence- 
as-violation, detracts from its power to describe violence-as-force, whereas Bufacchi (2005) accepts the existence of two ideologically different approaches to violence. These subtly different conceptions may be separable philosophically and conceptually but, within lived experiences, they exist to greater or lesser degrees as complex balances and blends (Dunning, 2008 [1983]).

Therefore, it should not be our goal to find any singular 'true' or 'correct' usage of the term - when discussing sports violence Goldstein $(1983,2)$ makes the point that no single definition "is either possible or desirable" - but rather we should attempt to find a conception that is adequately theorised relative to the important contributions of either position. That is to say, when considering whether or not, and how exactly, to describe something as 'violent', we ought to attend to the ways in which it constitutes both force and violation. As addressed later in this paper, such an approach requires methodological sensitivity to the social contexts of, and subjective experiences attached to, any given manifestation of 'violence'. With this initial point in mind, we now further explore attempts to obtain conceptual traction on 'violence' though an examination of typological accounts that seek to anchor this rather abstract debate within extant social phenomena.

\section{'Types' of Violence}

Galtung's (1981) call for an exhaustive and mutually exclusive typology may be a step too far for such a complex phenomenon, as behaviours which can be described by these two broad, partially overlapping and partially differentiated conceptions of violence resist easy categorisation and definition. However, engaging with the process of typological classification can provide the thematic and conceptual grounding required for a solid foundational knowledge of the concept. In this way, some of the inadequacies of implicit or anecdotal understandings of violence can in part be revealed. In what follows, we address five substantively different, although never completely discrete, categories of violence. This is by no means an exhaustive list, nor a proposed model for how violence ought to be imagined by scholars, but rather an attempt to highlight various ways in which violence tends to be conceptualised in academic literature.

Of these categories, interpersonal violence is perhaps that which is most commonly associated with the term violence (Audi, 1971; Coady, 1986). Physical in nature, direct interpersonal violence is manifest in bodily attempts to harm, abuse or kill others; whereas indirect forms aim to destroy or damage another's property. Such violence is mostly intentional and may be both instrumental (calculated/deliberate) and/or expressive (emotional/reactive) (Dunning, 2008 [1983]; Imbusch, 2003). Intimately tied to direct interpersonal violence, psychological violence implies a lack of physical harm; in its place, this causes emotional and psychological damage and distress (Audi, 1971). Here, gestures, symbols, words and images are used to elicit painful emotions in others (Cauchy, 1992; Dunning, 2008 [1983]; Imbusch, 2003). This separation of the physical and psychological may at times be conceptually useful, although applying such separation to all lived experiences risks failing to represent the multifaceted experience of violence; consider, for example, the physical and psychological trauma of sexual violence. Thus, sensitivity towards the difficulties of this conceptual separation is an important element of scholarly applications of these terms.

The previously described violences can be further contextualised by institutional violence. This statesanctioned violence is typically carried out by the military and police forces (Dunning, 2008 [1983]; Imbusch, 2003). The often taken-for-granted moral legitimacy that can accompany such acts is problematised when the term 'violence' is used to describe them. Examples of the death sentence, 
harmful means of restraint by police officers, treatment of prisoners of war and police tactics during riots and demonstrations highlight the political sensitivity that accompanies using the term 'violence' in this context. Within 'civilising' societies, these forms of legitimised violence persist, to some degree, where other forms of physical and psychological violence have gradually come under stricter internal and external control (Elias, 2000 [1939]). Institutional violence provides an important layer to an analysis of violence; it sensitises us to the often-arbitrary nature of dichotomous assumptions about the moral legitimacy of such actions.

The forms of violence described thus far can be defined using both the violence-as-force and violence-as-violation conceptions. However, the fault line between these two foundations begins to widen when symbolic violence becomes part of the analysis. Here, the essence of violence-as-force is (at least partly) removed and replaced by a focus on the violation of a victim or victims. Poverty, marginalisation, alienation and oppression are hallmarks of such violence. Symbolic violence carries with it "a power which presupposes recognition, that is, misrecognition of the violence that is exercised through it" (Bourdieu, 1991, 209). Bourdieu (1991) uses the term to describe the discrimination that is inherent within often taken-for-grated social institutions such as religion, the state, language and the gender order. Such violence is veiled and concealed behind unspoken, perhaps unconscious, acceptance of the norms and values attached to these social institutions which reproduce inequalities (Bourdieu, 1991).

Symbolic violences can be inconspicuous due, in part, to their ubiquity. There is a danger here of reifying social structures and removing any trace of the dense interdependencies that characterise the human interactions that cause such inequalities. Notwithstanding the need to be aware of such reification, employing the term symbolic violence, with its value-laden moral undertones, enables academics to highlight and challenge these less obvious forms of violation. By contrasting other, directly forceful manifestations of violence with the often more indirect force deployed by symbolic violence, we begin to notice markedly different applications of the two previously discussed philosophical definitions. However, while this and the preceding, more obviously 'forceful' examples of violence fit rather neatly within wider conceptions of violence-as-violation, in what follows, an example of violence-as-force which cannot be considered violation of the person in quite such an obvious sense is presented. As such, it proves to be one of the more contentious issues and debating points within definitions of violence (Audi, 1971).

Ritualised violence, of which central aspects of the action within contact sports such as boxing, rugby, ice hockey and wrestling are examples, is substantively different from the previously described forms of violence. This staged, managed violence - which exists within context-specific formal or informal norms of acceptability - is often expressly instrumental or theatrical in nature and holds a significant symbolic and sub-cultural component (Maguire, 1992; Matthews, 2014). Such violence involves a move away from the malicious intent to cause physical or psychological harm towards action targeted at achieving some other, generally socially acceptable objective (Dunning, 2008 [1983]). Often 'mimetic' of direct interpersonal violence and engaged in predominantly on a voluntary basis, examples of ritualised violence include sadomasochism (Chancer, 1992), professional wrestling (de Garis, 1999), and contact sports (Elias \& Dunning, 2008 [1986]).

Such ritual performances are fundamentally different from the violent acts of which they are a mimesis. Importantly, participants engaging in such ritualised violence are able to engender similar emotions and sensations to those experienced during 'real life' violent encounters, while avoiding some of the typical physical, psychological and social dangers associated with them (Atkinson, 2008; 
Maguire, 1992; Matthews, 2014). The emotions produced during ritualised violence, "are the 'sibling' of those aroused in real-life situations" (Maguire, 1992, 105). This form of violence may have the appearance of constituting violence-as-force - particularly when it results in physical trauma to participants, as is often the case - but it does not fit easily within the definition of violence-asviolation. In Audi's $(1971,59)$ words:

In most usual cases, violence involves the violation of some moral right ... there are cases, like wrestling and boxing, in which even paradigmatic violence can occur without violation of any moral right.

Importantly, and once more returning to our earlier comments about the interconnected nature of such experiences, ritualised violence "can involve elements of, or be transformed into, non-ritual violence" (Dunning, 2008 [1983], 225). Principally, such 'slippage' would include acts defined simultaneously through violence-as-force and -violation, such as when professional wrestlers take personal vendettas into a performance and deliberately harm their (unsuspecting) opponents (Smith, 2008), or when a contact sport athlete is pressured by a coach into harming their body through excessively rough and risky play (Messner, 1990; Young, 2012). Barring such obvious transgressions of the situational codes of legitimacy, ritualised violence is clearly experienced and understood differently than when the same actions are engaged in outside of their ritualised context. Grasping the notion of violence-as-violation, and attending to the subjective experience of being/feeling violated (or not), is key to understanding this complex behaviour, and perhaps thereby questioning the appropriateness of the term 'violence' to explain it.

Thus, through this typological discussion, the complex nature of violence becomes apparent. Applying any form of strict definition or static typology to frame such experiences may reduce the potential to portray an accurate picture of these multidimensional experiences. However, a failure to be cognisant of the multitude of ways in which violence might be conceptualised leaves an unsatisfactory looseness to accounts that attempt to explore such experiences. Indeed, without adequate attempts to engage with definitional literature, researchers often employ implicit understandings of violence, which can be read and interpreted in a variety of ways - perhaps including those which they were not themselves intending. In this regard, the preceding discussion does not offer a panacea to cure all our terminological and conceptual ills; rather, we seek to highlight the importance of engaging with foundational premises in order to move closer towards some level of explicit affirmation regarding the concept. With this in mind, we now turn more specifically to sports-related violence.

\section{Revisiting Foundational Typologies of Sports-Related Violence}

For Young (2000), the concept of sports violence is an elusive one. As shown above, being challenged to define the concept of violence in a general sense throws simplistic, taken-for-granted or implicit understandings into doubt. And when it comes to sport, this is as much the case for sports fans, members of sports' governing bodies and athletes as it is for academics (Young, 2000). Within his recent examination of sports-related violence (SRV), Young (2012) describes in depth the plethora of violences that are connected to sports worlds. Of the eighteen substantively different violences that Young (2012) identifies, our present paper focuses on phenomena that are perhaps most commonly imagined to constitute SRV; that is, on-field player violence. Early explorations of this type of SRV attempted to produce a level of analytical clarity via typological categorisation (Dunning, 2008 
[1983]; Smith, 1983), and it is to these we now turn, highlighting both the implicit and explicit contribution they can make to developing researchers' understanding of SRV.

\section{Smith's Typology}

Smith's influential socio-legal typology is implicitly based on a violence-as-force definition, but also incorporates a sensitivity to violence-as-violation. Smith identifies four types of direct interpersonal (physical) violence based on a scale of legal and (sub)cultural legitimacy. The first of these types, brutal body contact, is described as "significant bodily contact within the rules of a given sport" (Smith, 1983, 34). With the qualification of being integral to sporting activities, such as punching in boxing, these acts are in effect legal under the laws of the land despite often being illegal outside of their sporting contexts. Smith's hesitation to use the word 'violence' here is indicative of a sensitivity towards the consent that athletes give, either implicitly or explicitly, to trade such blows within the rules of the games they play; being mutually agreed upon, brutal body contact cannot directly constitute violence-as-violation. ${ }^{1}$ Meanwhile, borderline violence is that which does violate the official rules of a sport, but is still considered enough of a routine and normalised occurrence to be dealt with within the confines of a given match or game - such as a late tackle in rugby union. Again, the widespread acceptance that physically injurious fouls will happen as 'part of the game' stretches the notion of athletes' consent, problematizing the straightforward use of the term 'violence' here.

However, quasi-criminal violence is that which is considered unacceptable, violating the rules of the sport to such an extent that it also contravenes the laws of the land. This type of violence takes place in something of a legal 'grey area', wherein punishments are generally handed out by sports authorities rather than the judicial system, suggesting yet further tacit social acceptance of violent behaviours in sport. An example here would be mass brawling in team games - a match might be cancelled and fines or bans imposed, but the event would not necessarily lead to the criminal prosecution of those involved. Criminal violence, meanwhile, extends beyond any framework for acceptance within sport, and results in prosecution (Smith, 1983). Following from this criterion, Young (2012) suggests that Smith's typology suffers somewhat today for being slightly dated; pointing to the increasingly common nature of legal interventions into sport-related injuries, Young argues that Smith's categories are very often blurred in practice. Indeed, the definitional parameters of Smith's terminology can at times seem somewhat arbitrary, but we nevertheless believe that this model works well in conceptual terms, helping identify sports violences in a plural and contextual manner rather than as a single thing existing in the same sense across all sports worlds. Of further importance is Smith's careful handling of the word 'violence' itself; by refusing to use it for the most common and accepted group of behaviours, and qualifying it for those which exist at the 'borderline' of acceptability, Smith implicitly shows us to be cautious over our own use of the term.

\section{Dunning's Typology}

However, through its focus on relative legitimacy, Smith's work is less sensitive to some of the philosophical and conceptual issues previously discussed; within his socio-legal framing, much of the complex and overlapping nature of the experience of SRV are reduced and stripped away. In this regard, Dunning's (2008 [1983]) examination of violence, which draws on Weber's typology of action, offers a broader foundation from which to consider the experiential dimensions of SRV. He constructs a typology by defining a set of polarities and balances between salient elements of phenomena typically described as violent. In this way, such phenomena are not categorised as mutually exclusive types; rather, a grasp of the inherent complexity, dynamism and fluidity of such 
experiences can be gained. Violence is then conceptualised by Dunning as a set of balances between ritual/non-ritual, legitimate/illegitimate, armed/unarmed, physical/psychological, intentional/accidental, instigative/reactive and instrumental/expressive components (Dunning, 2008 [1983]). For Dunning, each act of violence is a blend of these intertwined polarities.

Such reasoning draws out much of the richness and complexity from lived experiences that might have otherwise been casually subsumed under the umbrella term of (sports-related) violence. However, we argue that the key contribution of this multi-faceted model to our appreciation of the social, physical and emotional significance of SRV are the balances between its ritual/non-ritual and legitimate/illegitimate components. This is due to the fact that examining the extent to which any potentially 'violent' action might be bound up in contextually-specific sporting ritual, or considered legitimate by members of athletic subcultures, requires examination from the point of view of those involved. This is particularly vital when we consider the importance of violence-as-violation, because grasping whether or not something constitutes a violation of a person clearly cannot be done without interrogating the person's lived experience of that thing. As such, the reasoning behind Dunning's model highlights the necessity of attending to individuals' lived experiences of 'violence' before we can confidently assign this morally evaluative label. In other words, the dimensions it requires us to account for underscore the need for sound empirical research into the specific meanings and values attached to sporting activities by their practitioners.

In what follows, we explore a selection of scholarly articles that have empirically examined SRV as a means of demonstrating the detail and utility of these models, and the lessons they both explicitly and implicitly teach us. It is hoped that this undertaking will provide practical examples of why it is important to engage with attempts to define player violence specifically, and SRV more broadly, when investigating this highly complex phenomenon.

\section{Player Violence in Contemporary Sociological Accounts of Sport}

The following sections therefore detail several examples from relatively recent literature wherein such a sensitivity to these prior works, and the vital theoretical labour that they have attempted, is missing. Importantly, it must be noted that this is not an exhaustive review of such research; there is not the space required within this paper to cast such a wide net while still drawing attention to, and adequately exploring, the key conceptual points we wish to make. Neither do we suggest this is a representative sample of the field. Rather, we have selected a sample that provides opportunities to demonstrate the importance of engaging with definitions of violence and SRV; delineating different 'types' of SRV; and understanding, in particular, its ritualistic, 'mimetic' dimensions.

\section{Defining violence - Pappas et al (2004) and Gill (2007)}

Pappas et al (2004) examined the relationship between 'on-ice' and 'off-ice' violence in ice hockey. Their aim was to "explore, through in-depth interviews with five former college/professional hockey players, the nature of aggression and violence in their sport and its relationship to violent interpersonal behaviours both inside and outside of sport" (Pappas et al, 2004, 293). Such an interesting piece of research demands a sophisticated understanding of the subtleties constituting players' representations and experiences of varied forms of violence. However, the subsequent definition of violence used for the paper fails to engage with the complexities outlined above in any meaningful way: "Violence is defined as male-to-male physical sport-related violence, male-to-male 
physical out-of-sport interpersonal violence, and male-to-female physical, sexual, and emotional aggression and abuse" $(2004,293)$. It is unclear what differences Pappas et al (2004) considered might exist between 'sport-related' and 'out-of-sport' violence, despite the fact that many other studies (e.g., Hughes \& Coakley, 1991; Messner, 1990; Maguire, 1992; Matthews, 2014, 2016; Young, 2000 ; 2012) of such phenomena emphasise complex, multifaceted, sometimes discrete and sometimes overlapping sets of experiences within and between them. Interestingly, they also appear to disregard the possibility of sexual violence occurring between men, or in any direction other than male-to-female.

This somewhat vague foundational conceptualisation then forms the basis of their exploration of these men's experiences of violence. Throughout the paper, violence is discussed with only minimal attempts to delineate the specific characteristics of such acts. Take the following example:

Players understand the possibility of violence on the ice, and know that fighting is advocated as a proactive means for not being easily intimidated and guarding against further aggression ... In general, there appears to be widespread support, both institutional and community, for violence associated with sport, both within and outside the sports context. (Pappas et al, 2004, 303)

Do all players accept the possibility of violence equally? Are they referring to all on-ice fighting here, or are there different forms that are seen to be more or less legitimate? Is it not the case that some violences would not be accepted by players, community members and institutions? And if such actors are largely accepting of (most) on-ice fighting, does this not in some way problematize labelling this particular behaviour as 'violence' to begin with? Overall, the extant relationship between legitimate, widely accepted forms of what Smith (1983) might deem 'brutal body contact' (or perhaps 'borderline violence') and illegitimate forms of direct interpersonal violence (culminating in a discussion of rape) is the focus of Pappas et al's paper. Yet through reading the five questions upon which their interviews were based, which broadly presuppose that there is a link between these violences $(2004,297)$, the methodological approach taken did not provide clear opportunities for participants to differentiate between the moral or experiential dimensions of these types of (apparent) violence; neither, for that matter, does the paper's analysis include any terminological or conceptual material through which readers might distinguish between them in these important ways.

Pappas et al's lack of clear definitions also impinged on their ability to draw out the richness of conclusions linked to masculinity - a common theme in SRV research. They argue that "embedded within many of these players' narratives is the implicit recognition that the tendency to draw parallels between manliness and violence extends beyond the competitive arena into broader social relations" (Pappas et al, 2004, 303). Are we to believe that these men associated all forms of violence with manliness? Or might there have been certain forms of (more-or-less legitimate) violence that can be more easily associated with masculine ideals, while other forms must be controlled or avoided? Ultimately, although the authors stopped short of outright claiming a causal link between the cultural celebration of 'on-ice violence' and the high incidence of sexual assault among male athletes more widely, such a relationship is clearly implied in this paper. It is as though the rough physicality of what "was viewed as a violent sport" $(2004,307)$ is a straightforward antecedent of sexual abuse, tied together around the construction of masculinity within ice hockey culture. Substantiated by data gathered from a very small sample, using what we interpret as rather closed 
and leading questions, we are left feeling that these authors have painted a rather simplistic picture of ice hockey players' perspectives on SRV.

The second paper we examine with respect to definitional clarity is Gill's (2007) exploration of 'violent' femininity. Here, experiences of physicality and ritualised violence within rugby are again viewed relative to interpersonal violence away from such sports worlds, and interpreted through a gender-sensitive analysis. Yet without the conceptual language needed to account for subtle differences between the ways in which these women signify their experiences, Gill runs the risk of overlaying her own interpretations of what constitutes 'violence' onto their accounts. Take the following example:

The improved body image is due to the women's participation in a violent and embodied context:

The actual game itself I enjoy... It's the physical... I like, not that you'd actually hurt somebody but you know what I mean? (Ciara). (Gill, 2007, 421)

Using Smith's typology, 'Ciara's' experiences of 'the physical', non-hurtful aspects of rugby might be most suitably defined as 'brutal body contact' (i.e., not clearly 'violence' as such); while in Dunning's model, clearly 'Ciara' approaches rugby's physicality without the intent to harm, and one must reasonably expect that the behaviours she describes are considered wholly legitimate within this sport. With this in mind, and lacking further clarification, it is challenging to find the 'violence' of rugby in this particular quotation, or in the others like it that Gill provides, particularly when employing a violence-as-violation definition.

Indeed, nowhere within Gill's (2007) account do we find out if her participants actually think of their engagement in rugby as 'violent'. This assumption of violence is particularly interesting when one considers some of the claims that Gill (2007) makes within her paper. In particular, she argues that, "in identifying themselves as violent protagonists and victims of violence they are able to articulate an independent and powerful position as women, and redefine what femininity means in such contexts" $(2007,425)$. Although this conclusion certainly resonates in part with our own perspectives on the experiences of women who engage in heavy contact sports (see AUTHORS), it is problematic that the data is presented without an exploration of how these women actually define the 'violence' of their rugby behaviours.

Such clarity is vitally important considering the morally evaluative nature of the term 'violence', particularly for discussions surrounding sex, gender, and feminist praxis. No doubt these women could engage in some actions which might be rightly defined as violent in some respect, but what is really needed is an attempt to find out how, and in what ways, these women themselves speak about and interpret the ritualised and interpersonal violences taking place within rugby. Without such an exploration, Gill's politically-minded conclusions appear to rest on her own account of rugby and its community, rather than the women whose lives she is attempting to represent. We dare say that many within the sport of rugby - and perhaps Gill's respondents themselves - would take issue with such an unproblematic labelling of their sport as 'violent'.

Typologies of violence - Guilbert (2004) 
These initial comments have highlighted the need to engage with some attempt at grasping or constructing reliable and workable definitions of what does or does not constitute 'violence' in various sports, with particular respect to the experiences of those people involved in them. Guilbert (2004) attempts to gain such conceptual clarity within a relatively recent typology ${ }^{2}$ of SRV. He begins with a bold but highly problematic opening statement: "News headlines featuring regular 'aggression' against footballer David Beckham, the prosecution brought against the Festina cycling team, or the Le Gougne affair in skating, among other stories hitting the front page, are clear evidence of the omnipresence of violence in sport" $(2004,45)$. Are we to believe, from these three anecdotal examples, that violence is 'omnipresent' in all sports? For a paper attempting to provide a foundational exploration of SRV, this is a very dubious beginning.

On the following page of the paper, Guilbert spells out a rough list of those types of violence he believes to be most common in sports:

In the field of 'competitive sporting events' (Bourdieu, 1980) violence in many forms may be observed. Physical violence (brawls, assaults, blows, falls), verbal violence (abuse, threats, protests), psychological violence (war of nerves, harassment, moral breakdown - 'blowing a fuse' as the phrase goes) and cheating (game fixing, corruption, match-rigging, taking of performance-enhancing drugs) are the most frequent forms of violence. $(2004,46)$

It seems, from the examples presented, that violence is used here as a 'catch-all' term to define any morally iniquitous activity associated with sport. Thinking back to our previous discussion of the wide and expansive definition potentially offered by conceiving of violence-as-violation, we might be able to find some academic merit to this. However, if one is to claim behaviours as diverse as assaults, falls, threats, game fixing, and doping all count as violence, some level of clarification and discussion around the conceptual, experiential, cultural and other differences existing between them would seem to be appropriate, but is nevertheless absent. We cannot help but feel that this neatly evidences Keane's (1996) objection to the un-checked employment of expansive definitions of violence-asviolation.

Notwithstanding this lack of clarity, a further, crucial dimension missing from Guilbert's attempted definition is an explicit reference to acts of apparent violence that occur within the formal and informal codes of any given sport. Later in the paper, Guilbert draws attention to some of these aspects of sports participation in a purely anecdotal, overly reductive manner:

We know that some sporting activities require physical contact. Such is the case of combat sports like Judo and Karate. The very purpose of these sports is to inflict violence and bodily harm on the opponent... Others imply physical contact. This is the case of team games such as soccer and basketball. If the aim is not to cause physical damage but achieve an object, winning often requires such damage. (Guilbert, 2004, 49-50)

This dichotomous understanding of such sports does an injustice to the complex way in which participants might negotiate aspects of ritual and interpersonal violence. Indeed, to suggest that physical contact is only 'implied' within soccer and basketball downplays the significance that localised and contextual understandings of violence might have within these social spaces. But moreover, the notion that sportized martial arts such as Judo and Karate are embedded with violent purpose is deeply problematic. Without an adequately theorised or justified definition of this term, its typical moral undertones sneak into Guilbert's reasoning and cast an ugly shadow over the sports 
he so casually labels as being fundamentally violent. Given the political implications of such a description, we could well suggest that this uncritical application of the word risks becoming a form of symbolic violence itself! ${ }^{3}$

Such conceptual errors lead us to conclude that the foundational understanding underpinning Guilbert's (2004) work is lacking in crucial dimensions. This is compounded by the manner in which he explored the area:

Along with sociologists who study blatant forms of violence rather than violence as such, I tried to approach violence in sporting areas indirectly, through its forms. I asked competitors the following question: 'How do you represent the main forms of violence in your sport?' (Guilbert, 2004, 47)

Ignoring the lack of clarity regarding the framing of ('blatant'?) violence here, the question he poses seems problematic from the outset; there is a clear assumption that violence was an aspect of these men's (no women were interviewed) experiences in and, importantly, interpretation of, their sport participation. Based on the data generated by asking this presumptuous and leading question, Guilbert (2004) then offers us three 'classes' as a means of categorising his findings: 'Hard Violence Sports', 'Soft Violence Sports' and 'Sports Where Violence does Not Exist or is Hidden'. In attempting to produce a broad typology based on different sports rather than different actions, behaviours and interpretations possible within said sports, Guilbert (2004) appears to be suggesting a restrictive, singular and wholly static image of each sport. It is difficult to see the ways in which this typology is an advancement of - for example - Smith's (1983) and/or Dunning's (2008 [1983]) works.

Indeed, we suggest that Guilbert's (2004) analysis represents a retrospective step that moves our understanding of sports violence more in line with unscientific, stereotypical assumptions about heavy contact sports than towards a genuine understanding of how SRV is experienced and given meaning in diverse ways by its practitioners. In this respect, perhaps the most pressing conceptual problem within Guilbert's (2004) paper is the apparent lack of conceptual space for the 'ritual' dimension of sports violence (Dunning, 2008 [1983]). Turning specifically to this phenomenon, we now examine a piece of research that explicitly critiques this 'mimetic' dimension of SRV.

\section{Ritual violence and mimesis - Pringle (2009)}

Pringle's (2009) exploration of rugby pleasures contains both substantive and conceptual problems. Perhaps due to space constraints imposed by his focus on pleasure, he neglects to engage with attempts to define the player violences that are a central aspect of his research. Specifically, his lack of thorough engagement with previous typological attempts to define SRV means his interpretation of rugby is skewed by his own assumptions. What is particularly frustrating in this respect is the manner in which he dismisses the ritual/mimetic element of such phenomena, simply by listing damage done to the bodies of his interviewees while participating in rugby, concluding that, "rugby pleasure, accordingly, does not appear well tempered or mimetic" $(2009,224)$. To discard this vital, experiential component of SRV simply due to the presence of injuries represents a misreading of the mimetic dimension to which Dunning (2008 [1983]) and Elias and Dunning (2008 [1986]) draw our attention, but it also signals a disregard for conceiving of violence-as-violation, illustrated through a simultaneous refusal to accept rugby players' own accounts of their experience of ritualised SRV. 
With respect to the concept of mimesis, participation in sports can be understood as generative of similar emotional experiences to what we might loosely call the 'real-life' situations of which they are a selective imitation (Elias and Dunning 2008 [1986]; Matthews, 2014). They have consequences which are usually less severe in an objective sense than those of their real-life equivalents, but, of far greater conceptual importance, consequences which are experienced differently by those involved. Mimetic experiences draw their value from both the potential similarity of emotional feeling they share with dangerous, 'violent', or otherwise socially illegitimate actions, and the differences in their meaning, purpose and typical consequences through which they are positioned as socially acceptable things which people can legitimately enjoy. This distinction has clear implications for the way in which acts might be labelled as violent, particularly when considering the notion of violence-asviolation, which itself requires a contextual sensitivity well-suited to exploring this balance of sameness and difference surrounding 'real' and mimetic experiences.

A fitting example here would be choking someone unconscious in a mixed martial arts match. Thrilling feelings through the immanence of danger, the ferocity of competition, or the sense of one's own physical power might accompany such an act, but the knowledge that one is doing so in order to fairly win a mutually agreed-upon, rule-bound contest, rather than forcefully assault or take another's life in a genuine fight for survival, confer moral legitimacy, along with a sense of ultimate safety, and even mutual respect upon this experience. This does not mean that the person being choked will not suffer pain, or cannot possibly be injured in some respect; indeed, injuries are common in this sport, although the ritual parameters surrounding it ('tapping out', the authority of the referee, etc.) clearly militate against the worst possible damage that might be done to athletes in these situations.

Rather than a totally pain/injury-free experience then, this mimetic form of violence represents a relatively controlled risk, enabling the generation of socially significant sensations and emotions, which selectively imitate those felt within 'real life' fights but remain understood and experienced differently by all involved. Yet in his analysis of rugby, Pringle (2009) misses the subtlety of this concept by means of an inability to conceptually differentiate between actions that result in bodily damage. Through a crude and poorly considered violence-as-force definition, the fact of rugby injuries is enough for Pringle to wave off the notion that rugby involves a mimetic dimension; that it is a socially legitimate, experientially different variation of other, similar actions (e.g., battles; mass brawls) which occur within altogether different structures of meaning (and also, for that matter, carry the potential to be far more injurious because of it).

Understanding this balance of similarities and differences, and how they are given meaning in practice, is only possible through interrogating the lived experiences of those involved in them. Yet while Pringle's (2009) paper is based on such empirical research, he fails to spell out the manner in which his participants' rugby injuries actually occurred. Without this information it is impossible for us to begin to appreciate the complexity of the framing of the actions that produce such injuries. Is it not possible that the most typical incidences of bodily damage in rugby occur via physical contact that not only conforms to the rules of the game (in Dunning's (2008 [1983]) typology, is legitimate), but are conducted without the intent to cause serious injury (accidental), might be followed by a handshake and jokingly re-lived over 'a beer at the pub' (ritual), and are generally constructed by all involved as 'just a part of the game' and 'not real violence anyway' (i.e., consensual and mimetic)? 
Indeed, despite Pringle's (2009) overt dismissal of the ritual aspect of rugby violence, he continuously quotes his interviewees and his own appreciation of the substantive difference between ritually legitimated and other types of violence. Take the following example:

Participants consent to being tackled or rucked and possibly even being punched, but the line is drawn with pain inflicting techniques such as eye gouging or ear biting. In this manner, rugby involves a perverse mix of institutionalised and unwritten rules concerned with the legitimacy of techniques of violence. (Pringle, 2009, 227)

Notions of consent and legitimacy are important components in understanding sporting and other forms of mimetic violence, such as S\&M practices, ${ }^{4}$ and are a key element of attempts to define violence-as-violation as outlined earlier. Although Pringle (2009) adopts a disappointingly dismissive and morally judgemental tone here ('perverse'), what he is inadvertently highlighting is the often consenting, pleasurable and legitimate nature of such experiences for participants, which separates ritualised SRV (tackling, rucking) from illegitimate, 'real' violence (eye gouging, ear biting).

Pringle (1992, 223, emphasis added) again makes a distinction between legitimate and illegitimate types of violence when he tells us that: "some of the interviewees, however, disapproved of overt violence in rugby." It appears that Pringle (2009) uses this term to describe interpersonal violence which clearly contravenes the rules and norms of the game (Smith's (1983) 'quasicriminal'/'criminal' violence, perhaps). He later quotes 'Morris' (Pringle, 2009, 227), who described the transgression of what he and other rugby players perceive as being a legitimate/illegitimate boundary: "I think there was a kind of acceptance, a kind of an unwritten rule that kicking somebody in the head was kind of marked or moved from acceptable violence to non-acceptable violence." However, it seems that Pringle's (2009) lack of engagement with attempts to provide an academic definition of player violence, and his particular rejection of the notion of mimesis, left him maintaining a primacy for his own understanding of violence-as-force, at times ignoring the importance of the meanings and definitions that the rugby players apply to their own actions on the field. Take the following example:

The interviewees suggested the idea that they participated in rugby to liberate innate tendencies for aggression or violence was farcical. In fact, all of the interviewees denied that they were violent even when discussing their participation in actions of unequivocal violence. (Pringle, 2009, 226 - emphasis added)

Are we to believe that this denial is nothing but a symptom of the ways in which these men are cultural dupes? Surely his participants' definitions of their actions, and the framing effect they have on rugby pleasures, are an important aspect of understanding these experiences? Is it also not the case that such acts, rather than being understood as 'unequivocal violence', are inherently equivocal with manifold variations in meaning and subjective definitions?

It is this simplistic reduction of the concept of violence that leads Pringle (2009) to miss the emotional significance and pleasure that is tied to the mimetic dimension of SRV. Instead of actually clarifying why it is that rugby players may at the same time respect each other and apparently commit forms of violence (-as-force) against each other, Pringle's (2009) analysis simply points implicitly to an issue that has been a central theme within the sociological analysis of player violence. That is, once again, that such action is very often experienced as substantively different to how the same actions would be in other social contexts. In short, many forms of SRV (and sport behaviours 
more generally) contain a mimetic dimension, through which certain actions - despite their risk of resulting in physical or other forms of harm - are ritually constructed and subjectively experienced by athletes as not being 'violent' at all.

\section{Concluding Remarks}

The aim of this paper has been threefold. Firstly, we have attempted to draw attention to some key concerns within foundational attempts to define violence. Secondly, the place in which sports violence operates within this conceptual landscape has been explored. Thirdly, we have attempted to highlight the importance of these earlier comments via a critical review of four papers that have studied player violence as a central theme. Of particular focus has been the tendency for some researchers to ignore the importance of defining the term violence, but in particular to overlook previous scholars' theorisations of player violence. While there are certainly problems within the foundational typological models we have discussed, some of which have been highlighted here, such works still represent useful attempts to further our understanding of sport worlds where apparently violent behaviours may play a significant role in lived experiences.

The final point we wish to make, in an attempt to move debates around sports violence forward, is that researchers of SRV need to be more cognisant of the need to adequately frame definitions of violence in their work, particularly with respect to prioritising the manner in which people actually engaged in sports understand and make sense of their apparent 'violence'. It is for this reason that, at several points within this paper, we have leant towards favouring a definition of violence which rests most heavily on violence-as-violation. We argue that only by faithfully attending to the interpretations of those invested within apparently violent sports can researchers hope to understand the subjective experiences that might - or might not - constitute violations of the person, and failing to do so often weakens analyses substantially.

Without such close-up interrogation, the temptation to use the term 'violence' on the basis of observed harm alone risks misrepresenting and casting unfair stigma upon certain sports and athletes. We dare say that in some cases, this arises from an uncritical reproduction of scholars' aesthetic distaste for certain sports rather than a genuine, well-theorised critique. And if, following Bourdieu (1984), we acknowledge that our tastes are largely a product of our positioning within social hierarchies, then overlaying aesthetic distaste with moral judgement within academic discourse risks reifying the specific tastes of more-or-less privileged scholars as the only legitimate lens through which to view apparently violent sport, returning to the issue of symbolic violence touched on briefly above. Ultimately, we argue that researchers intent on investigating SRV must carefully consider the conceptual platforms upon which they define, and use, what remains a deeply morally-loaded term if SRV scholarship is to do justice to the people and the phenomena it seeks to understand.

What then does our argument mean for the future study of research exploring SRV? Firstly, we argue that an essential step for scholars working in this area is to revisit foundational works which have explored how we can attempt to gain conceptual purchase on sports violence. The research papers we reviewed in the latter sections of this paper paid little regard to such works and were deficient in a variety of ways as a result. Rather than being followed dogmatically we suggest such early works represent a fantastic opportunity for contemporary scholars to engage in a dialogue around how we might understand, deconstruct and reconsider 'violence'. Secondly, there appears to be an 
opportunity to think again about violence by adopting a research methodology that pays far greater heed to the lives, experiences and definitions favoured by participants and practitioners who engage with apparent 'violence' on a regular basis. Indeed, we argue that in working with such people to explore and expand definitions of SRV, scholars would be far better placed to appreciate the subtleties and nuances of experiences of being the target and/or perpetrator of physically (or otherwise) injurious action within apparently 'violent' sporting contexts. It is here that we believe the sociological study of sports violence can be developed, and offer greater opportunity to shed light on social life more broadly.

\section{Notes}

1 There remains the possibility of conceptualising the normalised legitimacy of this (often) physically harmful behaviour as violence-as-violation if we consider the ways that many young men (in particular) are socialised into uncritically accepting the risks associated with it as they enter sporting subcultures (see Matthews, 2014; Messner, 1990). This theorising requires attention to the gendered, often racialized and commercially exploitive symbolic violences embedded within sport, and requires the presupposition that athletes are duped by the logic of sport and its proponents, rather than active agents who choose to take risks in order to play games involving 'brutal body contact'.

2 Previous typologies of sports violence were proposed in the 1980 s.

3 With respect to other martial arts/combat sports, the sport of mixed martial arts in particular has long 'fought for acceptance', as the title of Mayeda and Ching's (2008) text puts it, against this form of discursive stigmatisation. Being dismissed as violent and barbaric has had a tangibly negative impact on the sport's development, but does not fit well with how many practitioners and other aficionados conceive of and experience the sport and its moral landscape (e.g., Abramson and Modzelewski, 2011). That such treatment might adversely affect athletes' acceptance within wider communities, or limit the opportunities open to them to make a living through the sport, could provide the basis for positioning this treatment as a form of symbolic violence.

${ }^{4}$ As a brief aside, Pringle's attempt to problematize rugby violence by making a comparison to S\&M also misses the ways in which such acts are a pleasurable mimesis of 'real' sexual and other forms of interpersonal violence (Raj, 2010).

\section{References}

Abramson, C., and D. Modzelewski. 2011. "Caged Morality: Moral Worlds, Subculture, and Stratification among Middle-Class Cage-Fighters." Qualitative Sociology 34 (1): 143-175.

Atkinson, M. 2008. "Triathlon, Suffering and Exciting Significance." Leisure Studies 27 (2): 165-180.

Audi, R. 1971. "On the Meaning and Justification of Violence." In Violence, edited by J. A. Shaffer, 4599. New York, NY: David McKay.

Bourdieu, P. 1980. Questions de Sociologie. Paris: Minuit.

Bourdieu, P. 1984. Distinction: A Social Critique of the Judgement of Taste. Translated by R. Nice. Abingdon: Routledge.

Bourdieu, P. 1991. Language and Symbolic Power. Translated by G. Raymond and M. Adamson. Cambridge, MA: Harvard University Press.

Bufacchi, V. 2005. "Two Concepts of Violence." Political Studies Review 3: 193-204.

Cauchy, V. 1992. "Modern Societies and Innate Violence." International Social Science Journal 44: 210-216. 
Chancer, L. C. 1992. Sadomasochism in Everyday Life: The Dynamics of Power and Powerlessness. New Jersey: Rutgers University Press.

Channon, A., and C. R. Matthews, eds. 2015. Global Perspectives on Women in Combat Sports: Women Warriors around the World. Basingstoke: Palgrave Macmillan.

Coady, C. A. J. 1986. "The Idea of Violence." Journal of Applied Philosophy 3 (1): 3-19.

De Garis, L. 1999. "Experiments in pro Wrestling: Towards a Performative and Sensuous Sports Ethnography." Sociology of Sport Journal 16: 65-74.

Dunning, E. 2008[1983]. "Social Bonding and Violence in Sport." In Quest for Excitement: Sport and Leisure in the Civilising Process, edited by N. Elias and E. Dunning, 224-244. Dublin: University College Dublin Press.

Elias, N. 2000 [1939]. The Civilising Process: Sociogenetic and Psychogenetic Investigations. Translated by Edmund Jephcott. Oxford, Blackwell.

Elias, N., and E. Dunning. 2008[1986]. Quest for Excitement: Sport and Leisure in the Civilising Process. Oxford: Blackwell.

Galtung, J. 1981. "The Specific Contributions of Peace Research to the Study of Violence: Typologies." In Violence and Its Causes, edited by J. M. Domenach, 83-96. Fontenoy: Unesco.

Garver, N. 1977. "What is Violence?" In Social Ethics, Morality and Social Policy, edited by T. A. Mappes and J. S. Zembaty, 268-282. New York, NY: McGraw Hill.

Gill, F. 2007. "Violent' Femininity: Women Rugby Players and Gender Negotiation." Women's Studies International Forum 30: 416-426.

Goldstein, J. H. 1982. Sport Violence. New York, NY: Springer-Verlag.

Grundy, K. W., and M. A. Weinstein. 1974. Ideologies of Violence. Columbus, GA: Merrill.

Guilbert, S. 2004. "Sport and Violence - a Typological Analysis." International Review for the Sociology of Sport 39 (1): 45-55.

Hughes, R., and J. Coakley. 1991. "Positive Deviance among Athletes: The Implications of Overcomformity to the Sports Ethic." Sociology of Sport Journal 8: 307-325.

Imbusch, P. 2003. "The Concept of Violence." In International Handbook of Violence Research, edited by W. Heitmeyer and J. Hagan, 13-39. London: Kluwer Academic.

Keane, J. 1996. Reflections on Violence. London: Verso.

Kimble, N. B., A. S. Russo, B. G. Bergman, and V. H. Galindo. 2010. "Revealing an Empirical Understanding of Aggression and Violent Behaviour in Athletics." Aggression and Violent Behaviour 15: 446-462.

Litke, R. F. 1992. "Violence and Power." International Social Science Journal 132: 173-183.

Maguire, J. A. 1992. "Towards a Sociological Theory of Sport and the Emotions: A Process Sociological Perspective." In Sport and Leisure in the Civilising Process: Critique and Counter Critique, edited by E. Dunning and C. Rojek, 96-120. Hampshire: MacMilliam.

Matthews, C. R. 2014. "Biology Ideology and Pastiche Hegemony." Men \& Masculinties 17(3) 17(2): 99-119.

Matthews, C. R. 2016. "The Tyranny of the Male Preserve." Gender and Society 30 (2): 312-333.

Mayeda, D., and D. Ching. 2008. Fighting for Acceptance: Mixed Martial Arts and Violence in American Society. New York, NY: Universe.

Messner, M. 1990. "When Bodies Are Weapons: Masculinity and Violence in Sport." International Review for the Sociology of Sport 25 (3): 203-220.

Pappas, N. T., P. C. McKenry, and B. S. Catlett. 2004. "Athlete Aggression on the Rink and off the Ice. Athlete Violence and Aggression in Hockey and Interpersonal Relationships." Men \& Masculinities 6 (3): 291-312.

Platt, T. 1992. "The Concept of Violence as Descriptive and Polemic." International Social Science Journal 44: 185-191. 
Pringle, R. 2009. "Defamiliarizing Heavy-Contact Sports: A Critical Examination of Rugby, Discipline, and Pleasure." Sociology of Sport Journal 29: 211-234.

Raj, S. 2010. "Que(E)Rying Violence: Rethinking Pleasure, Harm and Intimacy in Lesbian Sadomasochism." Gay and Lesbian Issues and Psychology Review 6 (3): 135-148.

Salmi, J. 1993. Violence and Democratic Society. London: Zed Books.

Smith, M. D. 1983. "What is Sports Violence? A Sociolegal Perspective." In Sports Violence, edited by J. H. Goldstein, 33-45. New York, NY: Springer-Verlag.

Smith, R. T. 2008. "Pain in the Act: The Meanings of Pain among Professional Wrestlers." Qualitative Sociology 31 (2): 129-148.

Sorel, G. 1961. Reflections on Violence. New York, NY: Huebsch.

Young, K. 2000. "Sports Violence." In Handbook or Sports Studies, edited by J. Coakley and E. Dunning, 382-408. London: Sage.

Young, K. 2012. Sport, Violence and Society. Oxford: Routledge. 